\title{
Real-time Response Model to Optimize Refugee Flow
}

\author{
Baixue Liang \\ School of North China Electric Power University, Baoding 071000,China \\ 1186662586@qq.com
}

Keywords: Principal Component Analysis (PCA),Real-time Response Model

\begin{abstract}
Political turbulence in Syria, Afghanistan and Iraq has caused a drastic increase in Refugee flow to European countries. Also it is bringing a dilemma between protecting refugees and maintaining social stability to the major receiving countries. In this article, we developed a Real-time Response model to assess the refugee crisis after analyzing influential factors and optimize the refugee flow routes.

To begin with, we selected four decisive parameters to establish the simplified model, considering the situation of the homes of refugees, receiving countries and along the route. They are Capacity of receiving countries; Risk, representing the risk refugees have to take following a certain route; Duration, representing the time passing through different route takes; Condition of refugees' homes. To quantify each parameter, we build up a scoring system using Principal Component Analysis (PCA) based on the statistics offered in databases such as World Bank, IOM and UNHCR.

After the Scoring System was built, we applied our system on the six major immigration routes, before digging into each actual route from one point to another. Using the overall refugee population figure given by UNHCR in 2015, we optimized the refugee flow in each route combining our Scoring System with nonlinear programming. To test our model, three additional routes are evaluated and the refugee flow are optimized accordingly to verify our model applies.

Improving our model to become more realistic, Real-time Response Model is built to reflect the instantaneous situation of different refugee camp, therefore our Scoring System can fit for the continuously changing situation. The software Stella is adopted to simulate and visualize our Real-time Response Model that is set up using System Dynamics method. Capacity of receiving countries is analyzed as the decisive factor that is rapidly changing, as supplies from government organizations and non-government organizations ( NGO) is a dynamic factor. By refining our Scoring System using Real-time Response Model, a navigation system is set up to help lead refugees to their optimized route.

To put our model into actual practice, certain policies are required to support our model. It includes certain rate refugees being assessed, a free and quick flow of information, and so on.
\end{abstract}

\section{Introduction}

Refugee immigration has been an issue since biblical times, and became more intense every time when facing political and military turmoil. In recent years, social unrest caused by continuous war in Syria, Iraq and Afghanistan as well as poverty led from paralyzed economics resulted in massive influx of refugees in European countries. Because war and current policies have made getting a visa in war concerned countries almost impossible to most refugees, they had no choice but to escape their country violating customs laws. The commonly taken routes are depicted as follow, which lead to division in European governments on how to settle such large volume of refugees. Take Greece for example, as transportation hub of many migration routes, its policy restricting illegal boarding seems to be in vain, while German government is welcoming a large number of refugee everyday though public attitude was more or less affected by the "Paris Attacks" ${ }^{[1]}$.To deal with the complexity of migration phenomenon, some analysts suggested that the human displacements across space should be considered as a social process well-structured and organized as a socio-spatial system. Aiming to do so, we developed models to evaluate the refugee crisis and optimal refugee movement accordingly. 


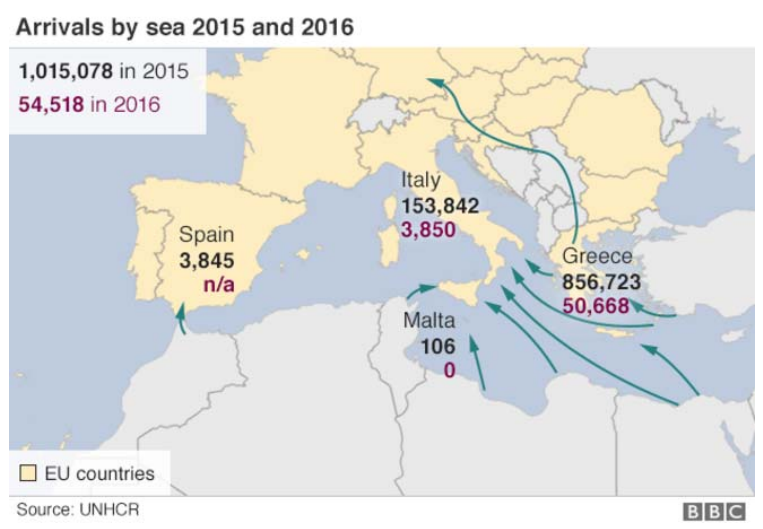

Fig.1 Major routes of refugee immigration

\section{Assumptions}

1. We assume that refugees migrates by boat when crossing the Mediterranean and migrates by train and on foot when they on land.

2. We assume that four factors in task 1 are linear independent.

3. We assume that statistic data can stand for the real situation.

4. We assume that current refugee population stands for European receiving country's willingness towards refugee.

\section{Symbol Definitions}

Table 3-1 Definition

\begin{tabular}{|c|c|c|}
\hline $\begin{array}{l}\text { Symbo } \\
\text { ls }\end{array}$ & Definitions & Units \\
\hline F1 & Capacity of the receiving country & unitless \\
\hline F2 & Duration & unitless \\
\hline F3 & Safety & unitless \\
\hline F4 & Condition of refugee country & unitless \\
\hline $\mathbf{F} 1_{\mathrm{i}}$ & F1 score of the receiving country $i$ & unitless \\
\hline $\mathbf{F} 2_{i}$ & F2 score of the route $i$ & unitless \\
\hline $\mathbf{F 3}_{\mathrm{i}}$ & F3 score of the route $i$ & unitless \\
\hline $\mathbf{F 4}_{\mathrm{i}}$ & F4 score of the refugee country $i$ & unitless \\
\hline $\mathbf{R}_{\mathrm{i}}$ & Total Score of crisis on the route $i$ & unitless \\
\hline $\mathbf{t}_{\mathrm{i}}$ & Settled refugees(per month) & cell \\
\hline $\mathbf{P}_{\mathrm{i}}$ & Probability to reach the destination on the route $\mathrm{i}$ & unitless \\
\hline $\mathbf{n}_{\mathrm{i}}$ & Predicted optimal refugee population on the route $\mathrm{i}$ & person \\
\hline $\mathbf{t}_{\mathrm{i} 0}$ & Duration on the route $\mathrm{i}$ & hour \\
\hline $\mathbf{t}_{\mathrm{i} 1}$ & Time to get an asylum on the route $\mathrm{i}$ & hour \\
\hline $\mathbf{T}_{\mathrm{i}}$ & Time to migrate successfully $\left(\mathrm{T}_{\mathrm{i}}=\mathrm{t}_{\mathrm{i} 0}+\mathrm{t}_{\mathrm{i} 1}\right)$ & hour \\
\hline $\mathbf{S U R}_{\mathrm{i}}$ & The survival rate on the route $i$ & unitless \\
\hline $\mathbf{R E J}_{\mathrm{i}}$ & The rejection rate of asylum in receiving country $i$ & unitless \\
\hline $\mathbf{R S}_{\mathrm{i}}$ & The refugee status of the receiving country $i$ & person \\
\hline $\mathbf{D R}_{\mathrm{i}}$ & Death rate of the route $i$ & unitless \\
\hline $\mathbf{O S}_{\mathrm{i}}$ & Overall score of the refugee country $i$ & unitless \\
\hline
\end{tabular}




\section{Refugee Crises Evaluation and Prediction}

Our goal is a model to evaluate the refugee crises with a lot of parameters such as the individuals themselves, the route refugees must take, the types of transportation and the countries' capacity.

We construct a model to analyze four factors which are condition of refugee states, safety and duration of refugee migration routes and capacity of the receiving countries. We choose a ranking table from World Bank which can tell the condition of refugee states as refugee countries criteria. We measure six of the most important refugee migration routes' distance and calculate duration of the migration process on six routes. We use death rate to measure the danger of each route. We choose every receiving country's refugee status as criteria to reflect receiving countries' attitude toward African refugees.

Then we integrate these criteria to measure refugee crisis using a score system we set and principal component analysis (PCA). So we develop a set of parameters and get total scores of refugee crisis, which stands for crisis level on six routes.

\subsection{Decisive Parameters}

First, to measure a refugee crisis, one of the most important parameters is the states' condition where most of refugees come from. A country's condition includes its economic development, education development, employment rate, whether it's in a war or not and so on. Considering these standards, we choose a ranking table which includes every country in the world. This ranking table integrates a lot of factors to measure a country's comprehensive strength and give every country a score, shown on Table 4-1. Country which gets the highest score means it has the biggest chaos so that refugee crisis is the most serious. The overall scores are as follows: (Total score is 4)

Table 4-1 Overall score of refugee country

\begin{tabular}{ccccccc}
\hline Country & Morocco & Libya & Albania & Iraq & Serbia & Ukraine \\
\hline OS & 1.92 & 2.45 & 1.94 & 3.38 & 1.85 & 2.55 \\
\hline
\end{tabular}

Source: World Bank

Second, we focus on the safety of each refugee migration routes. It stands for the risk of the route. The longer and more dangerous the route is, the more serious crisis refugees face. According to static data and our calculation, each route's death rate is as follows:

Table 4-2 Route and Death rate

\begin{tabular}{cc}
\hline Route & Death Rate \\
\hline R1.West Mediterranean & $7.8142 * 10^{-3}$ \\
R2.Central & 0.0169 \\
Mediterranean & UnableStatistics \\
R3.Albania to Greece & \\
R4.Eastern & $7.5358^{*} 10^{-4}$ \\
Mediterranean & UnableStatistics \\
R5.West Balkans & UnableStatistics \\
R6.Eastern Borders & \\
\hline
\end{tabular}

Source: bbc news

Third, we choose main refugee country and receiving country on every route. We assume that refugee migrate by boat, train and on foot at the most time. Then we estimate refugee migration duration on each route. The results are as follows: 
Table 4-3 Migration duration

\begin{tabular}{ccccc}
\hline Route & $\begin{array}{c}\text { Departure } \\
\text { country }\end{array}$ & $\begin{array}{c}\text { Receiving } \\
\text { country }\end{array}$ & Duration \\
\hline $\mathbf{1}$ & R1 & Morocco & Spain & About 24 hours(by boat) \\
$\mathbf{2}$ & R2 & Libya & Italy & About 48 hours(by boat) \\
$\mathbf{3}$ & R3 & Albania & Greece & About 168hours(on foot, by train) \\
$\mathbf{4}$ & R4 & Iraq & Greece & About 720 hours(on foot, by train) \\
$\mathbf{5}$ & R5 & Serbia & Hungary & About 168 hours(on foot, by train) \\
$\mathbf{6}$ & R6 & Ukraine & Hungary & About 168 hours(on foot, by train) \\
\hline
\end{tabular}

Fourth, we consider European receiving countries' condition. Their conditions have important relationship with refugees' migration. When receiving country give more asylums to refugees, refugee problem will be much better. So we choose refugee status in receiving country (2014) as capacity of the receiving country to reflect countries' willingness towards refugees, shown as Table 4-4.

Table 4-4 Refugee status in receiving country

\begin{tabular}{cccccc}
\hline Country & Spain & Italy & Greece & Greece & Hungary \\
\hline RS (2014) & 3918 & 50023 & 1248 & 1248 & 37963
\end{tabular}

\section{Source: UNHCR}

After the determination of four refugee crisis, we use a score system and run principal component analysis (PCA) to evaluate the level of refugee crisis on six routes. Each route's each factor gets a score and then we integrate them with the score function

$$
R_{i}=\alpha_{i 1} F_{1}+\alpha_{i 2} F_{2}+\alpha_{i 3} F_{3}+\alpha_{i 4} F_{4}(i=1,2,3,4,5,6) \text { to get the total score of each route. }
$$

\section{a) Scoring System}

\section{F1 Capacity of the receiving country}

Refugee status of the receiving country stands for the difference between applying asylum refugee population and rejected refugee population. When a country decide how many refugees it will receive, it take country's current economic situation and future development into consideration, so refugee status can reflect capacity of the receiving country. It is listed in Table 4-4. We set Italy's score as 100, so that each receiving country's score is $F 1_{\mathrm{i}}=\frac{R S_{\mathrm{i}} \times 100}{R S_{2}}$.

\section{F2 Duration}

We consider the location, public vehicles and distance between refugee departure country and receiving country. We get duration on every migration route. It is listed in Table 4-3. As same as F1's score system, we set 720 hour as score 100 , each route's score is $F 2_{\mathrm{i}}=\frac{t_{\mathrm{i} 0} \times 100}{t_{40}}$.

\section{F3 Safety}

When refugees get across the Mediterranean, the cause of the most death of them is shipwreck. According to reference static, we calculate the death rate of R1, R2and R4. It is listed in Table 4-2. We set 0.0169 as score $100, \mathrm{R} 1, \mathrm{R} 2$ and $\mathrm{R} 4$ 's score is $F 3_{\mathrm{i}}=\frac{D R_{\mathrm{i}} \times 100}{D R_{2}}$. Considering that the death rate on road is much smaller than it on the sea, we set the score of R3, R5 and R6 is 0.001 .

\section{F4 Condition of the refugee country}

The overall score stands for refugee country's current situation. It is listed in Table 4-1. We set the score of each country is $F 4_{\mathrm{i}}=\mathrm{OS}_{\mathrm{i}} \times 25$.

Each route's total score is as follows: 
Table 4-5 Score of each route

\begin{tabular}{ccccccc}
\hline & R1 & R2 & R3 & R4 & R5 & R6 \\
\hline F1 & 7.83 & 100 & 2.49 & 2.49 & 75.89 & 75.89 \\
F2 & 3 & 6 & 25 & 100 & 25 & 25 \\
F3 & 46.24 & 100 & 0.001 & 4.459 & 0.001 & 0.001 \\
F4 & 48 & 61.25 & 48.5 & 84.5 & 46.25 & 63.75 \\
\hline
\end{tabular}

\section{Principal component analysis (PCA)}

We calculate standardized matrix

$$
\mathrm{A}=\left(\begin{array}{cccc}
-0.8141 & -0.7808 & 0.5162 & -0.7316 \\
1.2548 & -0.6962 & 1.8299 & 0.1736 \\
-0.9339 & -0.1599 & -0.5048 & -0.6974 \\
-0.9339 & 1.9568 & -0.6138 & 1.7621 \\
0.7136 & -0.1599 & -0.6138 & -0.8512 \\
0.7136 & -0.1599 & -0.6138 & 0.3445
\end{array}\right) .
$$

Then we calculate eigenvectors and eigenvalues.

Table 4-6 Eigenvectors

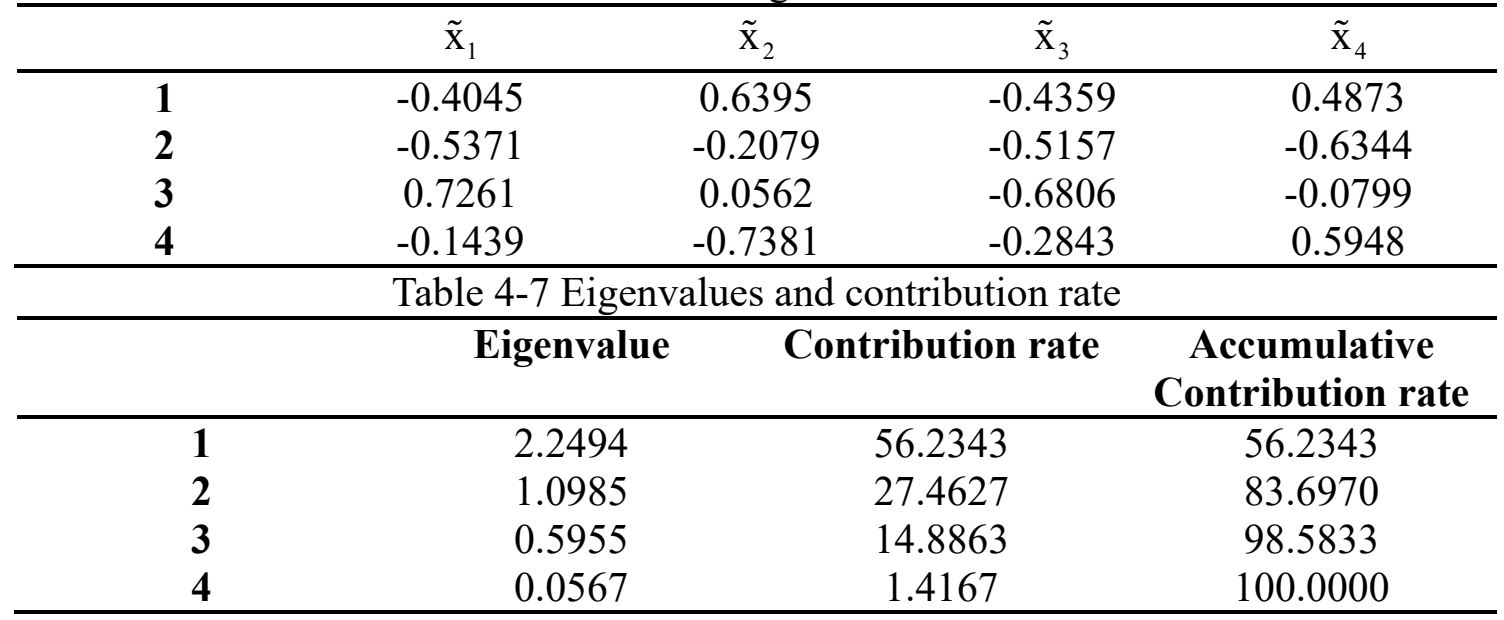

We can see that the sum of the first 3 component's contribution rate in Table 4-6 is more than $98 \%$, so we choose 1, 2and 3 as principle components. Three principle components are:

$\mathrm{Y} 1=-0.4045 * \mathrm{~F} 1+0.6395 * \mathrm{~F} 2-0.4359 * \mathrm{~F} 3+0.4873 * \mathrm{~F} 4$

$\mathrm{Y} 2=-0.5371 * \mathrm{~F} 1-0.2079 * \mathrm{~F} 2-0.5157 * \mathrm{~F} 3-0.6344 * \mathrm{~F} 4$

$\mathrm{Y} 3=0.7261 * \mathrm{~F} 1+0.0562 * \mathrm{~F} 2-0.6806 * \mathrm{~F} 3-0.0799 * \mathrm{~F} 4$

Using the PCA, we create the score system: $R=0.562343 \times \mathrm{Y} 1+0.274627 \times \mathrm{Y} 2+0.148863 \times \mathrm{Y} 3$

So the score function is:

$$
R_{i}=-0.26688 \times \mathrm{F} 1_{i}+0.31089 \times \mathrm{F} 2_{i}-0.4880 \times \mathrm{F} 3_{i}+0.0879 \times \mathrm{F} 4_{i}
$$

We calculate total score and the results are as follows:

Table 4-8 Total score of crisis level on each route

\begin{tabular}{ccccccc}
\hline Route & R1 & R2 & R3 & R4 & R5 & R6 \\
\hline Score of crisis & -0.7797 & -0.5597 & -0.2952 & 1.7001 & -0.2936 & 0.2281 \\
\hline
\end{tabular}

According to static, each route's refugee population (2014) is as follows:

\begin{tabular}{|c|c|c|c|c|c|c|}
\hline Route & R1 & R2 & R3 & R4 & R5 & $\overline{R 6}$ \\
\hline $\begin{array}{c}\text { Refugee } \\
\text { population }\end{array}$ & $\begin{array}{c}1559 \\
\text { (from } \\
\text { Morocco) }\end{array}$ & $\begin{array}{c}4317 \\
\text { (from Libya) }\end{array}$ & $\begin{array}{c}10463 \\
\text { (from } \\
\text { Albania) }\end{array}$ & $\begin{array}{c}377747 \\
\text { (from Iraq) }\end{array}$ & $\begin{array}{c}44648 \\
\text { (from } \\
\text { Serbia) }\end{array}$ & $\begin{array}{c}318606 \\
\text { (from } \\
\text { Ukraine) }\end{array}$ \\
\hline
\end{tabular}

Table 4-9 Refugee population

Source: UNHCR 
The number is much smaller than the total refugee population because on each route we just pick one refugee country. Then we use regression analysis to determine the relationship between score of crisis level and refugee population. We get a function:

$n_{i}=-2.906 \times 10^{5} \times R_{i}^{3}+2.294 \times 10^{5} \times R_{i}^{2}-5.684 \times 10^{5} \times R_{i}+1.765 \times 10^{5}$.

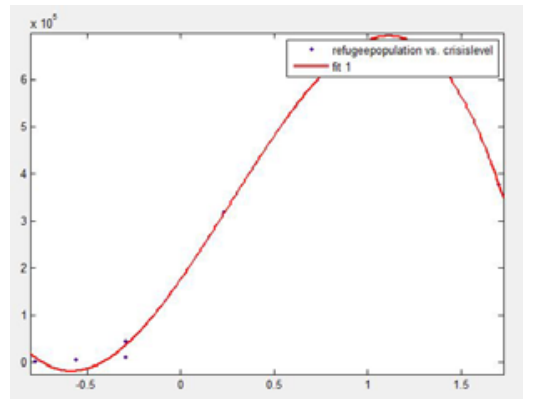

Fig. 4-1 Refugee population vs. score of crisis level

\section{Optimal Refugee Movement}

According to static, we calculate $\mathrm{P}_{i}$ by $P_{i}=S U R_{i} \times\left(1-R E J_{i}\right)$.

Table 5-1 Data on each route

\begin{tabular}{ccccccc}
\hline Route & $\mathbf{t}_{\mathrm{i}}$ & $\mathbf{P}_{\mathrm{i}}$ & $\mathbf{S U R}_{\mathrm{i}}$ & $\mathbf{1 - P}_{\mathrm{i}}$ & $\mathbf{R E J}_{\mathrm{i}}$ & $\mathbf{t}_{\mathrm{i} 0}$ \\
\hline $\mathbf{R 1}$ & 327 & 0.6479 & 0.9831 & 0.3521 & 0.3410 & $24 \mathrm{~h}$ \\
$\mathbf{R 2}$ & 4169 & 0.7735 & 0.9992 & 0.2265 & 0.2259 & $48 \mathrm{~h}$ \\
$\mathbf{R 3}$ & 104 & 0.0710 & 1 & 0.9290 & 0.9290 & $168 \mathrm{~h}$ \\
$\mathbf{R 4}$ & 104 & 0.0705 & 0.9928 & 0.9295 & 0.9290 & $720 \mathrm{~h}$ \\
R5 & 3164 & 0.8874 & 1 & 0.1126 & 0.1126 & $168 \mathrm{~h}$ \\
R6 & 3164 & 0.8874 & 1 & 0.1126 & 0.1126 & $168 \mathrm{~h}$ \\
\hline
\end{tabular}

Source: UNHCR

We consider transportation accessibility, safety of the route and countries' resource capacities. The goal is to construct a model to reflect refugee movement. We use nonlinear programming. Refugee population is related with four factors mentioned above, so we create an equation. The main refugee country's total refugee number is 7818409. (Source: UNHCR)

$$
\begin{aligned}
& \qquad f(x)=\frac{0.6479 \times n_{1}}{\frac{720 \times n_{1}}{327}+24}+\frac{0.7735 \times n_{2}}{\frac{720 \times n_{2}}{4169}+48}+\frac{0.071 \times n_{3}}{\frac{720 \times n_{3}}{104}+168}+\frac{0.0705 \times n_{4}}{\frac{720 \times n_{4}}{104}+720}+\frac{0.8874 \times n_{5}}{\frac{720 \times n_{5}}{3164}+168}+\frac{0.8874 \times n_{6}}{\frac{720 \times n_{6}}{3164}+168} \\
& \text { Restrictions are s.t. }\left\{\begin{array}{l}
n_{i}>0(i=1,2,3,4,5,6) \\
n_{1}+n_{2}+n_{3}+n_{4}+n_{5}+n_{6}=7818409
\end{array}\right.
\end{aligned}
$$

Our goal is to make more refugees be settled in unit time, so we use Lingo to solve this nonlinear programming problem. When $f(x)$ reaches its maximum, the results of $n^{i}$ are as follows:

Table 5-2 Predicted optimal refugee population on route $\mathrm{i}$

\begin{tabular}{ccccccc}
\hline Route & R1 & R2 & R3 & R4 & R5 & R6 \\
\hline $\mathbf{n}_{i}$ & 98376.05 & 1937972 & 27376.45 & 56434.82 & 2946991 & 2946991 \\
\hline
\end{tabular}

So we determine optimal refugee population on each route.

We add three more routes to our model to predict refugee population on these three routes, shown as Table 5-3. 
Table 5-3 Data on the route 7, 8 and 9

\begin{tabular}{lccccc}
\hline $\begin{array}{l}3 \text { more } \\
\text { routes }\end{array}$ & $\begin{array}{c}\text { Departure } \\
\text { country }\end{array}$ & $\begin{array}{c}\text { Receiving } \\
\text { country }\end{array}$ & $\begin{array}{c}\text { Capacity of } \\
\text { receiving } \\
\text { country }\end{array}$ & $\begin{array}{c}\text { Overall score of } \\
\text { departure country }\end{array}$ & Duration \\
\hline R7 & Mali & Switzerland & 13677 & 2.47 & 2 weeks \\
R8 & Tunisia & Belgium & 16032 & 2.00 & 1 week \\
R9 & Iraq & France & 17025 & 3.38 & 1 month \\
\hline
\end{tabular}

Resource: UNHCR $5-4$.

Using the score system we set in task 1 , we calculate score of route 7, 8 and 9, shown as Table

Table 5-4 Score of route 7,8 and 9

\begin{tabular}{lccc}
\hline & F1 $_{i}$ & F2 $_{i}$ & F4 $_{i}$ \\
\hline R7 & 27.34 & 50 & 61.75 \\
R8 & 32.05 & 25 & 50 \\
R9 & 34.03 & 100 & 84.5 \\
\hline
\end{tabular}

Although we can just use the same score system in task 1 to evaluate the new three routes, we integrate the whole 9 routes and use the principle component analysis (PCA) and score system mentioned in task 1 to get a more precise result.

Table 5-5 New score of each route

\begin{tabular}{cccccccccc}
\hline Route & R1 & R2 & R3 & R4 & R5 & R6 & R7 & R8 & R9 \\
\hline \multirow{2}{*}{$\mathbf{R}_{i}$} & -0.806 & -0.548 & -0.483 & 1.546 & -0.666 & -0.109 & 0.151 & -0.576 & 1.492 \\
& 7 & 7 & 0 & 6 & 1 & 4 & 3 & 3 & 3 \\
\hline
\end{tabular}

Using the regression analysis with R1 R6's scores and refugee population in Table 10, we get the new function between crisis score and refugee population.

$n_{i}=-5.666 \times 10^{5} \times R_{i}^{3}+1.966 \times 10^{5} \times R_{i}^{2}+1.023 \times 10^{5} \times R_{i}+4.216 \times 10^{5}$

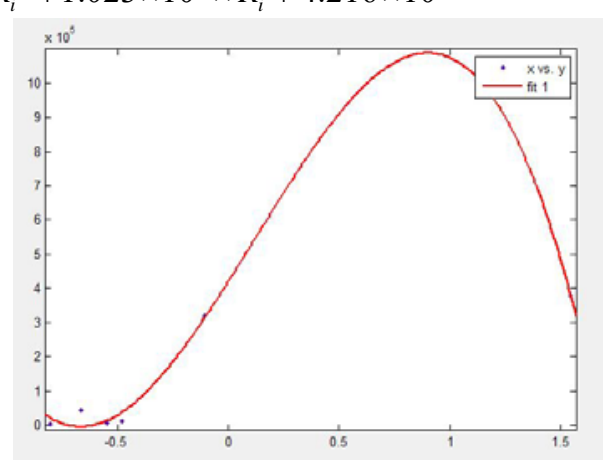

Fig. 5-1 New refugee population vs. score of crisis level

Using this function, we get the results, shown as Table 5-6.

Table 5-6 Total score of crisis level and predicted optimal refugee population on route 7,8 and 9

\begin{tabular}{cccc}
\hline Route & R7 & R8 & R9 \\
\hline $\mathbf{R}_{i}$ & 0.1513 & -0.5763 & 1.4923 \\
$\mathbf{n}_{i}$ & 578889 & 5759.66 & 502965 \\
\hline
\end{tabular}

\section{- Sensitivity Analysis}

We test our model in each route's refugee population for various changes. We change the data of route 1 and see a sharp change in result. The result proves that our model is sensitive.

- We change the $t_{1}$ by up to $20 \%$ and use nonlinear programming to solve

$$
f(x)=\frac{0.6479 \times n_{1}}{\frac{720 \times n_{1}}{392.4}+24}+\frac{0.7735 \times n_{2}}{\frac{720 \times n_{2}}{4169}+48}+\frac{0.071 \times n_{3}}{\frac{720 \times n_{3}}{104}+168}+\frac{0.0705 \times n_{4}}{\frac{720 \times n_{4}}{104}+720}+\frac{0.8874 \times n_{5}}{\frac{720 \times n_{5}}{3164}+168}+\frac{0.8874 \times n_{6}}{\frac{720 \times n_{6}}{3164}+168}
$$


With restrictions: s.t. $\left\{\begin{array}{l}n_{i}>0(i=1,2,3,4,5,6) \\ n_{1}+n_{2}+n_{3}+n_{4}+n_{5}+n_{6}=7818409\end{array}\right.$

The refugee population on each route are, shown as Table 5-7.

Table 5-7 New predicted optimal refugee population on route i (1)

\begin{tabular}{ccccccc}
\hline Route & R1 & R2 & R3 & R4 & R5 & R6 \\
\hline $\mathbf{n}_{i}$ & 117731.8 & 1933104 & 27307.37 & 56300.06 & 2939436 & 2744530 \\
\hline
\end{tabular}

We observe a $19.67 \%$ increase in $n_{1}$, a $0.25 \%$ decrease in $n_{2}$, a $0.25 \%$ decrease in $n_{3}$, a $0.23 \%$ decrease in $\mathrm{n}_{4}$, a $0.26 \%$ decrease in $\mathrm{n}_{5}$, a $0.24 \%$ decrease in $\mathrm{n}_{6}$.

- We change the $\mathrm{P}_{1}$ by up to $20 \%$ and use nonlinear programming to solve $f(x)=\frac{0.77748 \times n_{1}}{\frac{720 \times n_{1}}{327}+24}+\frac{0.7735 \times n_{2}}{\frac{720 \times n_{2}}{4169}+48}+\frac{0.071 \times n_{3}}{\frac{720 \times n_{3}}{104}+168}+\frac{0.0705 \times n_{4}}{\frac{720 \times n_{4}}{104}+720}+\frac{0.8874 \times n_{5}}{\frac{720 \times n_{5}}{3164}+168}+\frac{0.8874 \times n_{6}}{\frac{720 \times n_{6}}{3164}+168}$ With restrictions s.t. $\left\{\begin{array}{l}n_{i}>0(i=1,2,3,4,5,6) \\ n_{1}+n_{2}+n_{3}+n_{4}+n_{5}+n_{6}=7818409\end{array}\right.$, the refugee population on each route is:

Table 5-8 New predicted optimal refugee population on route $\mathrm{i}(2)$

\begin{tabular}{ccccccc}
\hline Route & R1 & R2 & R3 & R4 & R5 & R6 \\
\hline $\mathbf{n}_{i}$ & 107545.7 & 1935786 & 27353.40 & 56455.01 & 2943258 & 2748010 \\
\hline
\end{tabular}

We observe a $9.32 \%$ increase in $n_{1}$, a $0.11 \%$ decrease in $n_{2}$, a $0.08 \%$ decrease in $n_{3}$, a $0.04 \%$ increase in $\mathrm{n}_{4}$, a $0.13 \%$ decrease in $\mathrm{n}_{5}$, a $0.12 \%$ increase in $\mathrm{n}_{6}$.

- We change the $\mathrm{T}_{10}$ by up to $20 \%$ and use nonlinear programming to solve

$f(x)=\frac{0.6479 \times n_{1}}{\frac{720 \times n_{1}}{327}+28.8}+\frac{0.7735 \times n_{2}}{\frac{720 \times n_{2}}{4169}+48}+\frac{0.071 \times n_{3}}{\frac{720 \times n_{3}}{104}+168}+\frac{0.0705 \times n_{4}}{\frac{720 \times n_{4}}{104}+720}+\frac{0.8874 \times n_{5}}{\frac{720 \times n_{5}}{3164}+168}+\frac{0.8874 \times n_{6}}{\frac{720 \times n_{6}}{3164}+168}$ With

restrictions: s.t. $\left\{\begin{array}{l}n_{i}>0(i=1,2,3,4,5,6) \\ n_{1}+n_{2}+n_{3}+n_{4}+n_{5}+n_{6}=7818409\end{array}\right.$, the refugee population on each route are:

Table 5-9 New predicted optimal refugee population on route $\mathrm{i}(3)$

\begin{tabular}{ccccccc}
\hline Route & R1 & R2 & R3 & R4 & R5 & R6 \\
\hline $\mathbf{n}_{i}$ & 107645.5 & 1935704 & 27366.91 & 56322.69 & 2943398 & 2747972 \\
\hline
\end{tabular}

We observe a $9.4 \%$ increase in $\mathrm{n}_{1}$, a $0.12 \%$ decrease in $\mathrm{n}_{2}$, a $0.03 \%$ decrease in $\mathrm{n}_{3}$, a $0.2 \%$ decrease in $\mathrm{n}_{4}$, a $0.12 \%$ decrease in $\mathrm{n}_{5}$, a $0.12 \%$ decrease in $\mathrm{n}_{6}$.

\section{Real-time Response Model}

Our established model is based on the factors such as capacity, risk, duration and individual attributes remain a constant over a fairly long period of time, a week for example. However, that is often not exactly the case in refugee migration. Refugees need to face rapidly changing circumstances in terms of the risks they need to take on different routes, the capacity of different entry points of receiving countries and individual attributes. Thus, the parameters considered in our model should change accordingly to reflect the dynamic situation, in order to build a Real-time Response model.

\subsection{Parameter Analysis}

The various factor that may influence migration flow have been sorted into four parameter in our model: capacity, risk, individual attributes, duration. While risk, individual attributes and duration( the time it takes in migration) are influenced by exogenous event alone, the capacity of different entry points in different countries can change drastically determined by the supply in refugee camps, refugee population and other resources such medical aid, security forces, education, etc. Therefore capacity becomes the major push-pull factor that changes with time. In the simplified real-time response model that is build, food supply and refugee flow are considered as the dynamic 
factors, while other parameters are considered as a constant.

\subsection{Real-time Response model}

Considering the systematic mechanism of Refugee flow, we adopted System Dynamics method to further study the problem. System Dynamics as a method to study complicated dynamical systems was developed in 1956. It is based on the principle of feedback control in conjunction with the analysis of the logic in dynamic behavior, thereby describe the system architecture and simulation system ${ }^{[2]}$.To be able to simulate Refugee flow in a certain refugee camp we used Stella as a tool to predict refugee population and the resources in the care center, the real-time prediction model is shown as Fig. 6-1.

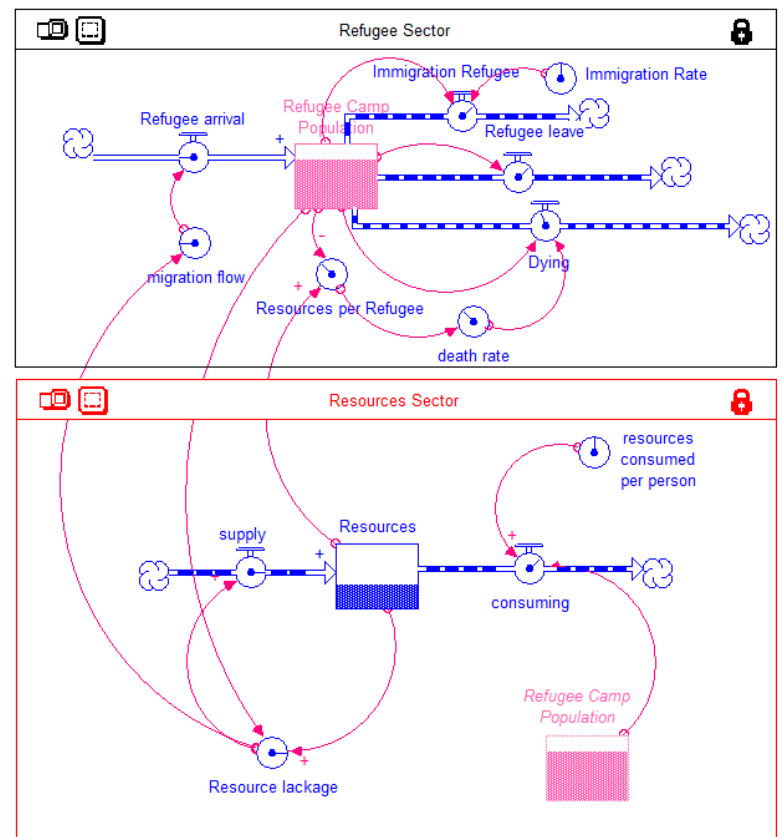

Fig. 6-1 The real-time prediction model of refugee population and left resources in a refugee camp In this model refugee leave rate is set to be $\frac{1}{30}$, to support the cycle in refugee camps. Death rate is set to be related to the resources per refugee:

Death rate $=\frac{\text { Resources_per_Re fugee }}{\text { Initial_Resources_per_Re fugee }} \times 0.0025$

Resources consumed per person $=1$

Initial Resources $=5000$ packages

Initial Population of Refugee $=1000$

Initial Immigration rating $=0.1$

When the left resources in the refugee camp was less than $50 \%$, than organizations will supply 7500 packages. When the left resources in the refugee camp was over $50 \%$, the refugee camp will let 300 refugees in. The model responds by day. The real-time prediction results of refugee population, resources supply capacity and early warning at Immigration rating $=0.1$ in a refugee camp, is shown as Fig. 6-2. 


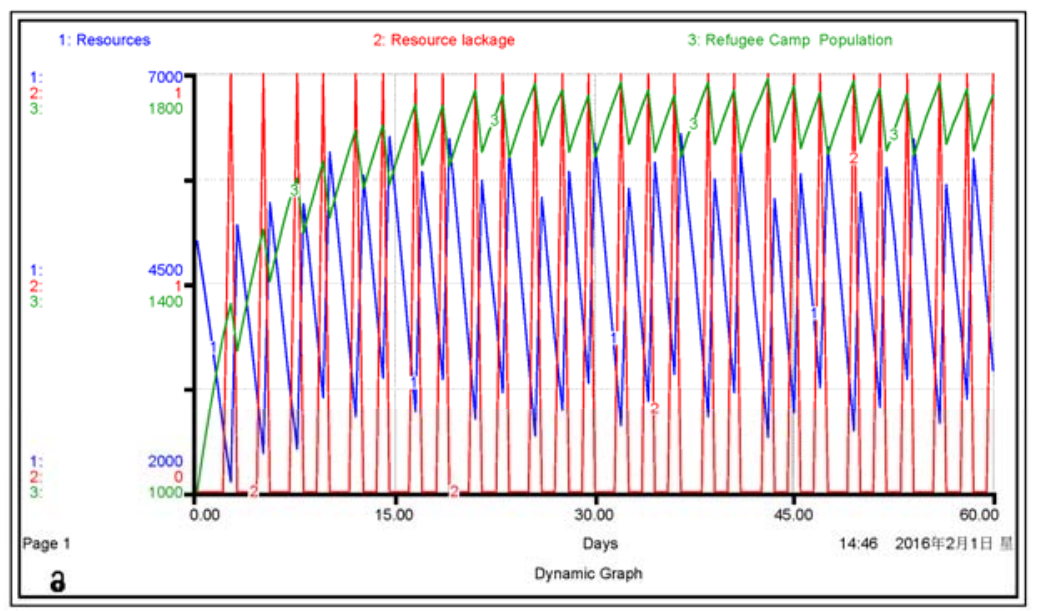

Fig. 6-2 The real-time prediction results of refugee population, resources supply capacity and early warning at immigration rate $=0.1$ in a refugee camp

Table 6-1 The real-time operation state parameters at immigration rate $=0.1$ in a refugee camp during a week

\begin{tabular}{|r|r|r|r|r|r|r|}
\hline $13: 46 \quad 2016 / 2 / 1$ 量期一 & \multicolumn{7}{|c|}{ Table 1 (Operational State Table) } \\
\hline Days & Resources & consuming & migration flow & Refugee Camp Po & Immigration Rating & death rate \\
\hline .0 & $5,000.00$ & $1,000.00$ & 300.00 & $1,000.00$ & 0.10 & $2.500000 \mathrm{e}-003$ \\
\hline .5 & $4,500.00$ & $1,082.08$ & 300.00 & $1,082.08$ & 0.10 & $2.079322 \mathrm{e}-003$ \\
\hline 1.0 & $3,958.96$ & $1,158.82$ & 300.00 & $1,158.82$ & 0.10 & $1.708186 \mathrm{e}-003$ \\
\hline 1.5 & $3,379.55$ & $1,230.58$ & 300.00 & $1,230.58$ & 0.10 & $1.373158 \mathrm{e}-003$ \\
\hline 2.0 & $2,764.26$ & $1,297.69$ & 300.00 & $1,297.69$ & 0.10 & $1.065068 \mathrm{e}-003$ \\
\hline 2.5 & $2,115.42$ & $1,360.49$ & 0.00 & $1,360.49$ & 0.10 & $7.774472 \mathrm{e}-004$ \\
\hline 3.0 & $5,185.17$ & $1,269.26$ & 300.00 & $1,269.26$ & 0.10 & $2.042596 \mathrm{e}-003$ \\
\hline 3.5 & $4,550.54$ & $1,333.35$ & 300.00 & $1,333.35$ & 0.10 & $1.706436 \mathrm{e}-003$ \\
\hline 4.0 & $3,883.87$ & $1,393.32$ & 300.00 & $1,393.32$ & 0.10 & $1.393747 \mathrm{e}-003$ \\
\hline 4.5 & $3,187.21$ & $1,449.46$ & 300.00 & $1,449.46$ & 0.10 & $1.099447 \mathrm{e}-003$ \\
\hline 5.0 & $2,462.48$ & $1,502.03$ & 0.00 & $1,502.03$ & 0.10 & $8.197154 \mathrm{e}-004$ \\
\hline 5.5 & $5,461.46$ & $1,401.28$ & 300.00 & $1,401.28$ & 0.10 & $1.948739 \mathrm{e}-003$ \\
\hline 6.0 & $4,760.82$ & $1,456.50$ & 300.00 & $1,456.50$ & 0.10 & $1.634339 \mathrm{e}-003$ \\
\hline 6.5 & $4,032.57$ & $1,508.21$ & 300.00 & $1,508.21$ & 0.10 & $1.336876 \mathrm{e}-003$ \\
\hline 7.0 & $3,278.47$ & $1,556.65$ & 300.00 & $1,556.65$ & 0.10 & $1.053051 \mathrm{e}-003$ \\
\hline 7.5 & $2,500.14$ & $1,602.06$ & 0.00 & $1,602.06$ & 0.10 & $7.802923 \mathrm{e}-004$ \\
\hline
\end{tabular}

\subsection{Immigration rate optimization}

Using the model above, we altered the parameter, Immigration rate to optimal refugee flow. Immigration rate represents the efficiency of refugees being dealt with, either be granted asylum or rejected.

$$
\text { Immigration rate }=\frac{\text { application_dealt_with_each_day }}{\text { Re fugee_population_in_the_camp }}
$$




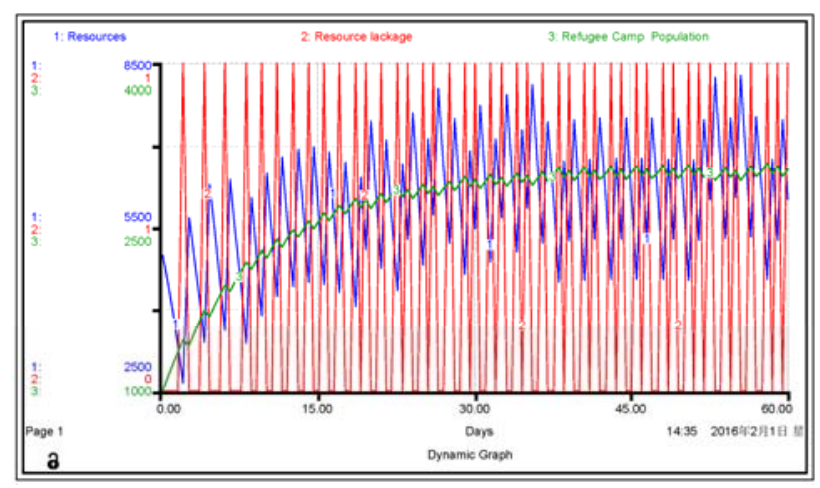

(a) Immigration rate $=0.025$

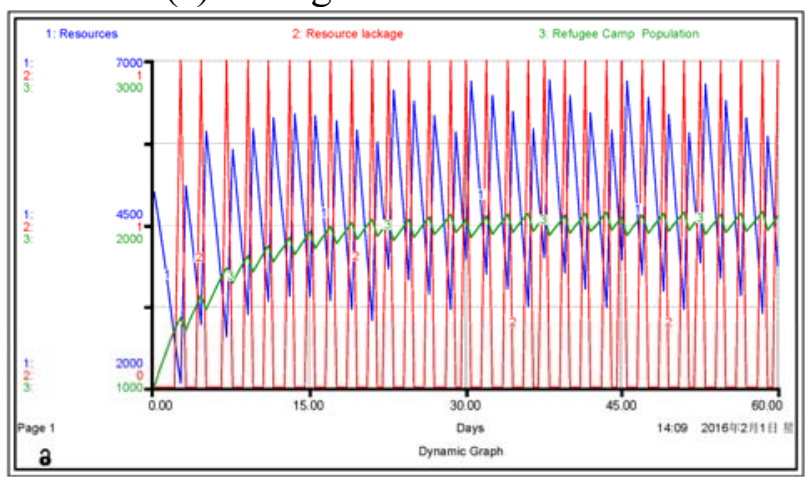

c) Immigration rate $=0.075$

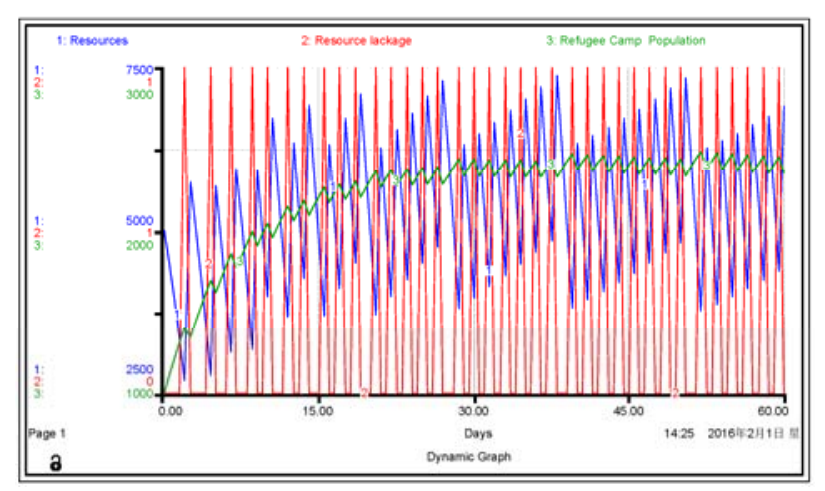

(b) Immigration rate $=0.05$

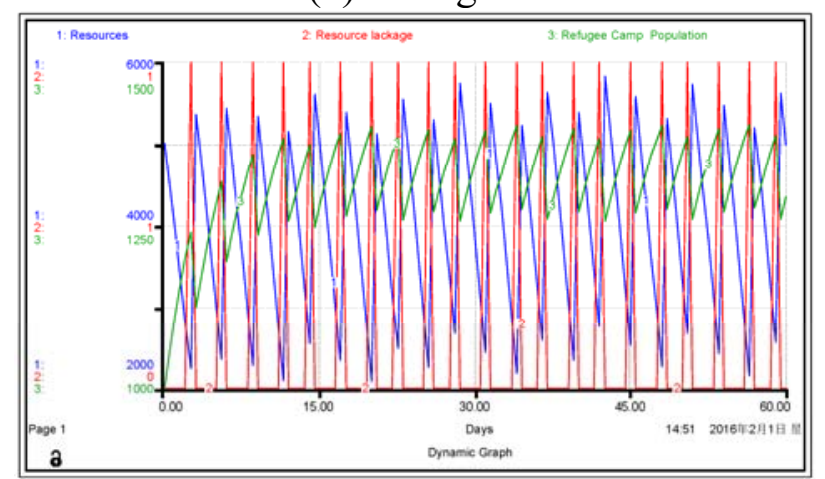

(d) Immigration rate $=0.15$

Fig. 6-3 The real-time prediction results of refugee population, resources supply capacity and early warning at alternative Immigration rates in a refugee camp

All figure tables are attached in the Appendix. According to the results, when setting immigration rate at 0.05 , the cluster situation in refugee camps can be greatly mitigated.

The refugee camp will require supply every 1.5 day.

\subsection{Refugee route optimization}

Though we fail to import actual data from different refugee camps because of a lack of data, we built up a real-time response model to simulate and predict resources and refugee population in refugee camps. After collecting death rate, overall score, duration between each route, granted-asylum population, and other figures for the factor to be considered, an crisis evaluation function can be easily built using the method we adopted in 2.1 .

\subsection{Refugee route optimizing application}

To guide refugees to their optimized route, we applied our crisis evaluation function on navigation.

Dijkstra's algorithm[3] as a well-developed algorithm is adopted here and altered to optimize refugee route. Considering the situation refugees are confronting, we set the crisis level(W(uv)) between each route as the length value. The function $1(\mathrm{u})$ represents the given name (number) of different points.

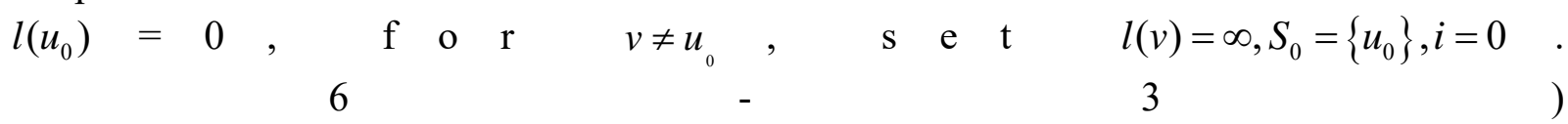

1)For each $v \in \overline{S_{i}}\left(\overline{S_{i}}=V \backslash S_{i}\right)$,

2) $\min _{u \in S_{i}}\{l(v), l(u)+w(u v)\} \rightarrow l(v)$, calculate $\min _{v \in \bar{S}_{i}}\{l(v)\}$ when $l\left(v_{i}\right)$ reaches minimum value, $v_{i} \rightarrow u_{i+1}, S_{i+1}=S_{i} \cup\left\{u_{i+1}\right\}$

3) If $i=|V|-1$, then stop calculating, else $i+1 \rightarrow i$, return to 2 )

We simplified our model to 6 points (entry points, transit points or exit points) a set the crisis level on each branch, which are depicted in the following table: 
Table6-2 the crisis level set for each branch

\begin{tabular}{ccccccc}
\hline crisis & a & b & c & d & e & f \\
\hline a & 0 & 50 & Inf & 40 & 25 & 10 \\
b & & 0 & 15 & 20 & Inf & 25 \\
c & & & 0 & 10 & 20 & Inf \\
d & & & & 0 & 10 & 25 \\
e & & & & & 0 & 55 \\
f & & & & & & 0 \\
\hline
\end{tabular}

The crisis level of going to different points from point a are 35(a to b), 45(a to c), 35(a to d), 25(a to e), 10(a to f). Thus, the optimized choice is to head to point $\mathrm{f}$.

\section{Policy}

In order to put our model into practice, and to take effect in alleviate refugee crisis, there are several policies necessary.

1)The United Nations and European Union should cooperate to put effort in promoting peace in countries that is suffering from war, and help rebuild the infrastructure to settle the displaced people are the core to defuse the refugee crisis eventually.

2)Displaced people should be the main concern of every nation, and should be quickly accessed to give certificate that legalize their identity in European in order to free their movement or reject so that they be repatriated, therefore mitigate the cluster effect in transit countries such as Greece and Turkey. Under the circumstance, refugees from countries at war should be a priority over refugees only trying to escape from poverty.

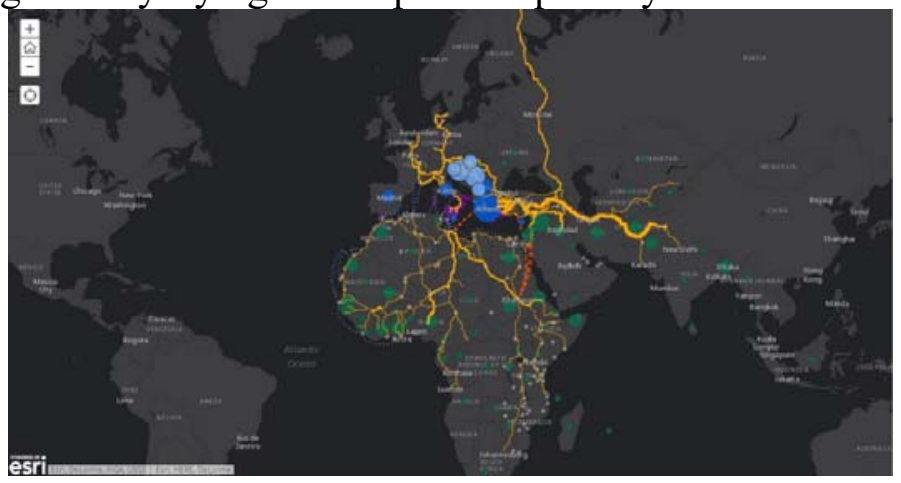

Fig.7-1 Refugee immigration route map across Africa and Europe

3)A real-time information system should be built to update latest data of each refugee camp and route, especially the population of refugee and the supply storage in each camp. The rapid consumed resources in different camp should have priority in transportation according to the attributes in different refugee camp.

4) Volunteers for education and social security should be recruited world-wide in order to ease the xenophobia in the receiving countries, at the same time quickly transform refugees to become self-supporting.

\section{Strengths and Weaknesses}

\subsection{Strengths}

1) In task 1, we offer a model to predict the optimal refugee population on six routes.

2) In task 2, we consider three more routes besides the six routes. The result can stand the analysis in task 5.

3) In task 3, we construct a dynamic model to measure the dynamic of refugee crisis. It takes resources from government organizations and non-government organizations into consideration.

4) System Dynamic method is based on logic and simple function that relate to different parameters, which improved the feasibility of our Real-time Response Model.

5) The results of our models agree with common sense. 


\subsection{Weakness}

1) Some statistic data is from 2014. If we use current data, our result will be much perceive.

2) Factors of refugee migration may be over-simplified. The actual situation may be more complicated.

3) Because some parameters' data are not available, we set these parameters based on semi-educated guesses.

\subsection{Scalability}

To test the scalability of our real-time response model, the migration flow, the population of refugees that is allowed in each time increase tenfold and the population of refugees accommodated in the camp is expanded by a factor of ten.

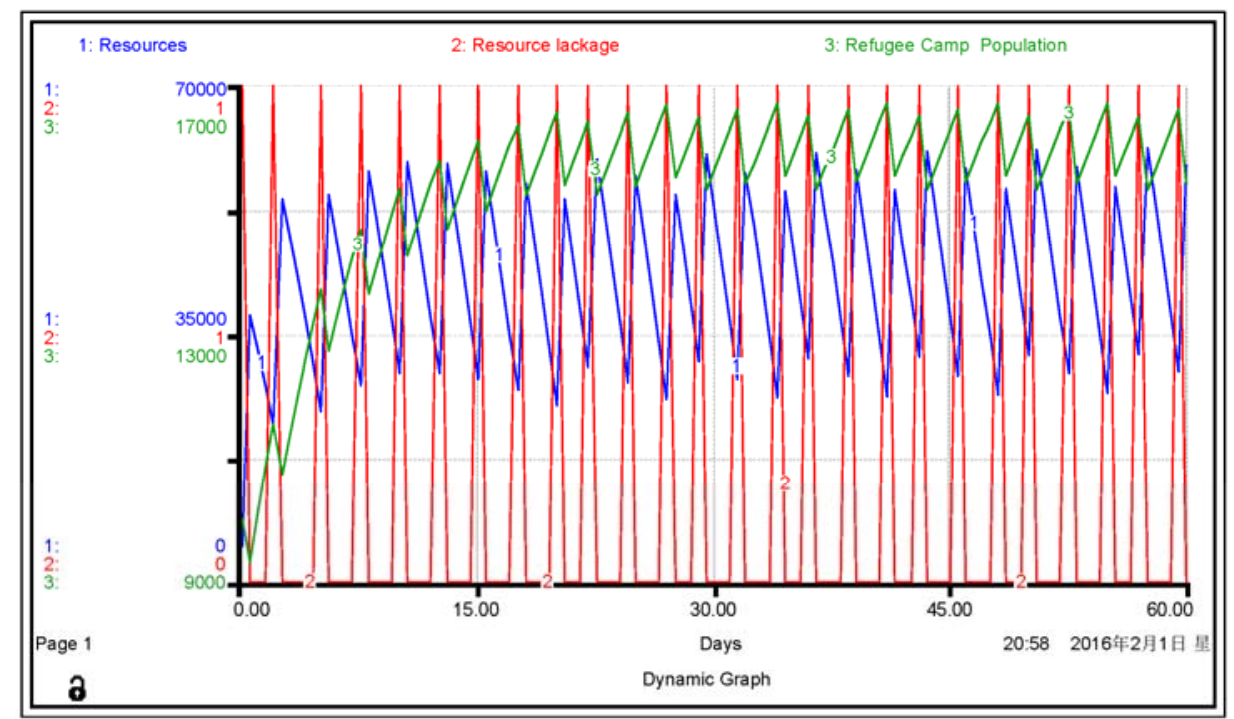

Fig. 8-1 The real-time prediction results of refugee population, resources supply capacity and early warning at immigration rate $=0.1$ in a refugee camp size expanded to ten times

Table 8-1 The real-time operation state parameters at immigration rate $=0.1$ in a refugee camp size expanded to ten times during a week

\begin{tabular}{|c|c|c|c|c|c|c|}
\hline Days & Resources & consuming & migration flow & Refugee Camp Po & Immigration Rating & death rate \\
\hline .0 & $5,000.00$ & $10,000.00$ & 0.00 & $10,000.00$ & 0.10 & $2.500000 \mathrm{e}-003$ \\
\hline .5 & $37,500.00$ & $9,320.83$ & $3,000.00$ & $9,320.83$ & 0.10 & 0.020116 \\
\hline 1.0 & $32,839.58$ & $10,105.69$ & $3,000.00$ & $10,105.69$ & 0.10 & 0.016248 \\
\hline 1.5 & $27,786.74$ & $10,849.88$ & $3,000.00$ & 10,849.88 & 0.10 & 0.012805 \\
\hline 20 & $22,361.79$ & $11,557.09$ & 0.00 & $11,557.09$ & 0.10 & $9.674492 \mathrm{e}-003$ \\
\hline 25 & $54,083.25$ & $10,730.71$ & $3,000.00$ & 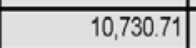 & 0.10 & 0.025200 \\
\hline 3.0 & $48,717.89$ & $11,380.12$ & $3,000.00$ & \begin{tabular}{|l|}
$11,380.12$ \\
\end{tabular} & 0.10 & 0.021405 \\
\hline 3.5 & $43,027.83$ & $11,999.65$ & $3,000.00$ & $11,999.65$ & 0.10 & 0.017929 \\
\hline 4.0 & $37,028.00$ & 12,592.11 & $3,000.00$ & $12,592.11$ & 0.10 & 0.014703 \\
\hline 4.5 & $30,731.95$ & $13,160,06$ & $3,000.00$ & $13,160.06$ & 0.10 & 0.011676 \\
\hline 5.0 & $24,151.92$ & $13,705.90$ & 0.00 & 13,705.90 & 0.10 & $8.810777 \mathrm{e}-003$ \\
\hline 5.5 & 54,798.97 & $12,731.79$ & $3,000.00$ & $12,731.79$ & 0.10 & 0.021521 \\
\hline 6.0 & $48,433.07$ & $13,246.01$ & $3,000.00$ & $13,246.01$ & 0.10 & 0.018282 \\
\hline 6.5 & $41,810.07$ & $13,741.86$ & $3,000.00$ & 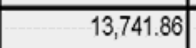 & 0.10 & 0.015213 \\
\hline 7.0 & $34,939.14$ & $14,221.21$ & $3,000.00$ & $14,221.21$ & 0.10 & 0.012284 \\
\hline 7.5 & $27,828.54$ & $14,685.78$ & 0.00 & 14,685.78 & 0.10 & $9.474655 \mathrm{e}-003$ \\
\hline
\end{tabular}

As is depicted, the impact of sudden crisis that expanded by a factor of ten will lead to a drastic decrease on the capacity of refugee camp and a temporary flux in the consumption of resources. But the impact can be quickly mitigated under former policy. If alter the supply accordingly the impact can be mitigated even faster. 


\section{Refinement of our Model}

Our original real-time response model considered three out flow of refugees: Dying, refugee leave, Immigration Refugee. The factor refugee leave and Immigration refugee are related, and should be combined.

At the same time, the parameters set in this model show low efficiency of the refugee camp. After analysis, organizations should supply 7500 packages when the left resources in the refugee camp was less than $5 \%$, giving organizations a period to respond as well. When the resources in refugee camp was over $5 \%$, refugee camps will let in 500 more refugees.

The simulation shows high efficiency in resource use, and the population of refugees in refugee camp remain a fairly steady state.

To further refine our model in accuracy and scale, we need to collect more data in terms of different entry points. We need to conclude more factors into the model such as education resources, medical aid and so on, so that our model can represent predict more of the actual situation.

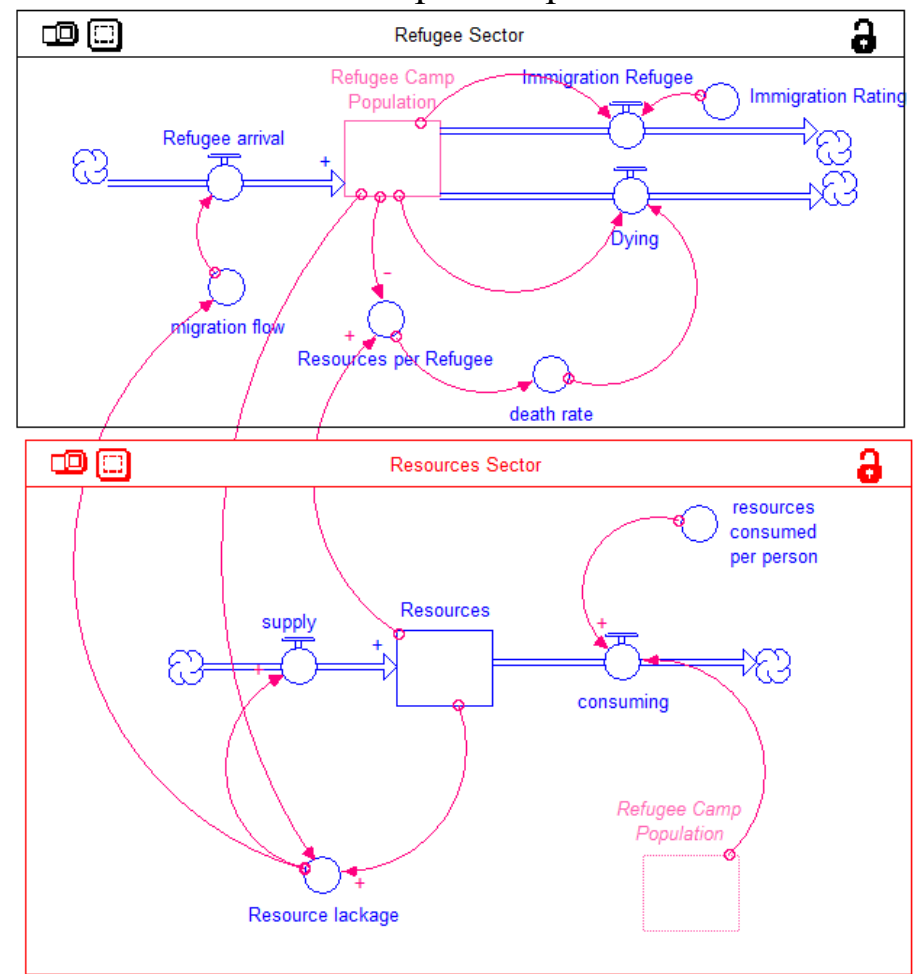

Fig. 9-1 The refined real-time response model of refugee population and left resources in a refugee camp

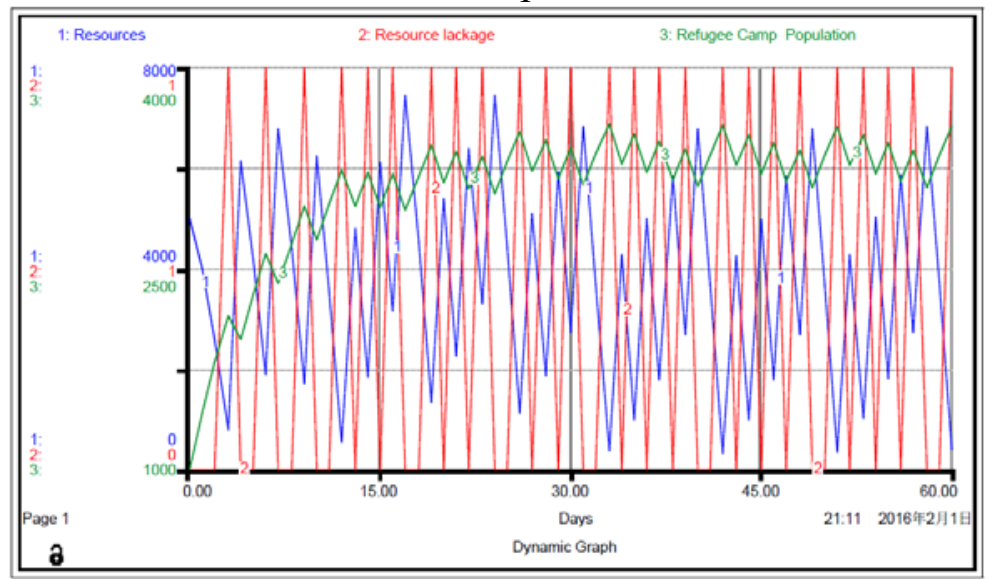

Fig. 9-2 The refined real-time prediction results of refugee population, resources supply capacity and early warning at immigration rate $=0.083$ in a refugee camp 


\section{References}

[1] Kritz, M. and H. Zlotnik. 1992 "Global interactions: migration systems, processes and policies". International migration systems, A global approach. Clarendon Press, Oxford, UK.

[2] Cheng Hongshan, Wang Yan, Li Shaoshan and Sun Ruyong, 2007.8 "APPLICATIONS OF DYNAMICS SOFTWARE STELLA IN ECOLOGY". Journal of South China Normal University(Natural Science Edition).

[3] Si Shoukui, Sun Zhaoliang. "Mathematical Modeling Algorithms and Applications". ISBN 978-7-118-10037-2, 2015.4: 40-42. 